\title{
PD-L1 expression correlated with p53 expression in oral squamous cell carcinoma
}

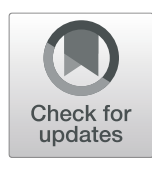

\author{
Itaru Tojyo ${ }^{1 *}\left(\mathbb{D}\right.$, , Yukari Shintani ${ }^{1}$, Takashi Nakanishi ${ }^{1}$, Kenjiro Okamoto ${ }^{1}$, Yukihiro Hiraishi ${ }^{2}$, Shigeyuki Fujita', \\ Mayu Enaka ${ }^{3}$, Fuyuki Sato ${ }^{3}$ and Yasuteru Muragaki ${ }^{3}$
}

\begin{abstract}
Background: Programmed cell death ligand 1 (PD-L1) is an immune checkpoint molecule that attenuates the immune response. PD-L1 contributes to failed antitumor immunity; thereby, blockade of PD-L1 with monoclonal antibody enhances the immune response. Recently, it was reported that PD-L1 was regulated by protein 53 (p53). Besides, cytokeratin 17 (CK17) is thought to be a diagnostic marker of oral squamous cell carcinoma (OSCC). Our aim was to evaluate the correlation between the immunohistochemical expression of PD-L1, p53 and CK17 with clinicopathological characteristics and disease-specific survival in patients with OSCC.

Methods: A total of 48 patients with OSCC were included in this study. Immunohistochemical staining was performed to evaluate the correlation among the expressions of PD-L1, p53 and CK17, and furthermore the correlation among various clinicopathological factors, PD-L1, p53 and CK17.
\end{abstract}

Results: The positive rate of P53, CK17, PD-L1 (tumor cells) and PD-L1 (tumor-infiltrating lymphocytes) was 63.2\%, 91.7\%, 48.9\% and 57.1\%. A statistically significant correlation between p53 expression and T stage and TNM stage ( $p=0.049, p=0.03$, respectively) was observed. Also, a statistically significant correlation between p53 and PD-L1 (TCS) expression ( $p=0.0009$ ) was observed. Five-year disease-specific survival rate was not significantly correlated with gender, TNM stage, p53 expression, PD-L1 expression and CK17 expression.

Conclusion: The expression of P53 and PD-L1 shows significantly positive correlation in oral squamous cell carcinoma in tumor cells. Also, a significant correlation between p53 expression and T stage and TNM stage was observed. No other significant correlation between PD-L1 staining or CK17 and clinical or pathologic characteristics was identified.

Keywords: Oral squamous cell carcinoma (OSCC), Programmed death ligand 1 (PD-L1), Protein 53 (p53), Cytokeratin 17 (CK17), Immunohistochemistry, Disease-specific survival rate

\section{Background}

Programmed death ligand 1 (PD-L1) is a cell-surface protein that has been proved to be overexpressed on various cells including tumor cells, lymphocytes and other tissues in many human cancers [1]. PD-L1 promotes $\mathrm{T}$-cell tolerance and escape host immunity. It is reported that increased PD-L1 and PD-1 expression is predictive of nodal metastasis and poor prognosis in oral squamous cell carcinoma $[2,3]$.

Protein 53 (p53) is one of the most commonly mutated genes in cancer [4]. It is critical in regulating cell

\footnotetext{
* Correspondence: kagoky@wakayama-med.ac.jp

'Department of Oral and Maxillofacial Surgery, Wakayama Medical University, 811-1 Kimiidera, Wakayama, Wakayama 641-8509, Japan

Full list of author information is available at the end of the article
}

division, apoptosis, senescence and DNA damage and repair. p53 is also important for modulating the immune response. When DNA is damaged, p53 gene transcription is increased and wild-type p53 protein is concentrated, which result in the arrest of cell cycle at the G1/S phase and apoptosis of cancer cells. When the p53 gene is mutated, the mutant p53 protein loses its cancer inhibition function and promotes the transformation of normal cells to malignant cells. Mutant p53 is present in almost all types of human malignant tumor. Also, mutant p53 is closely correlated with oral squamous cell carcinoma [5-7].

Cytokeratins (CKs), intermediate filament of the cytoskeletons, are candidates for diagnostic markers of OSCC, as they are overexpressed in OSCC compared to 
normal mucosa. The significant up-regulation and the strong overexpression of CK17 could exhibit its utility as a diagnostic marker of OSCC [8-10].

In this study, we aimed to evaluate the correlation between the immunohistochemical expression of PD-L1, p53 and CK17 with clinicopathological characteristics and disease-specific survival in patients with OSCC.

\section{Methods}

The study comprised a total of 49 selected patients (29 males and 20 females) with oral squamous cell carcinomas (OSCCs) at the Department of Oral and Maxillofacial Surgery, Wakayama Medical University Hospital, between 1990 and 2010. Patients were randomly selected. This study followed the Declaration of Helsinki on medical protocol and ethics, and the regional ethical review board of Wakayama Medical University approved the study (Protocol Identification Number 2512).

The patients ranged in age from 49 to 91 years, with a mean age of 65.7 years. The primary malignant tumors were located on the lower gingiva in 18 cases, the tongue in 11 cases, the upper gingiva in 5 cases, the oral floor in 7 cases, the maxillary sinus in 3 cases, the hard palate in 2 cases, and the soft palate in 3 cases. Tumor staging was performed according to the specifications of the TNM classification of malignant tumors (UICC 1997). The mode of tumor invasion was assessed according to the classification by Yamamoto et al as follows: grade 1 = well-defined borderline; grade 2 = cords, less marked borderline; grade 3 = groups of cells, no distinct borderline; and grade $4=$ diffuse invasion $(4 \mathrm{C}=$ cordlike type; $4 \mathrm{D}=$ widespread type) [11].

\section{Immunohistochemical staining}

The PD-L1, P53 and CK17 expression OSCC tissues were evaluated from serial deparaffinized sections. The OSCC biopsy specimens had been fixed with formalin from 24 to $48 \mathrm{~h}$ at room temperature and treated with routine processing as in a previous study $[12,13]$. Four micrometer-thick sections of paraffin-embedded tissues were mounted on precoated slides and air-dried overnight at $58^{\circ} \mathrm{C}$. The serial sections were prepared for staining and were incubated with primary antibodies for $12 \mathrm{~h}$. Immunohistochemistry (IHC) was performed using a Discovery Auto-Stainer with automated protocols (Ventana Medical Systems, Inc.; Roche) as previously described $[13,14]$.

The following commercial antibodies were purchased: PD-L1 (1:1, rabbit monoclonal, 790-4905; Ventana Medical Systems, Inc.; Roche, USA), p53 (1:100, mouse monoclonal, M7001; Dako Denmark, Glostrup, Denmark) and CK17 (1:50, mouse monoclonal, M7046; Dako Denmark, Glostrup, Denmark).

\section{Evaluation of staining results}

The tumor biopsy sample was considered positive for PD-L1 expression in tumor cells if moderate-to-strong membrane staining was observed in $\geq 5 \%$ of tumor cells

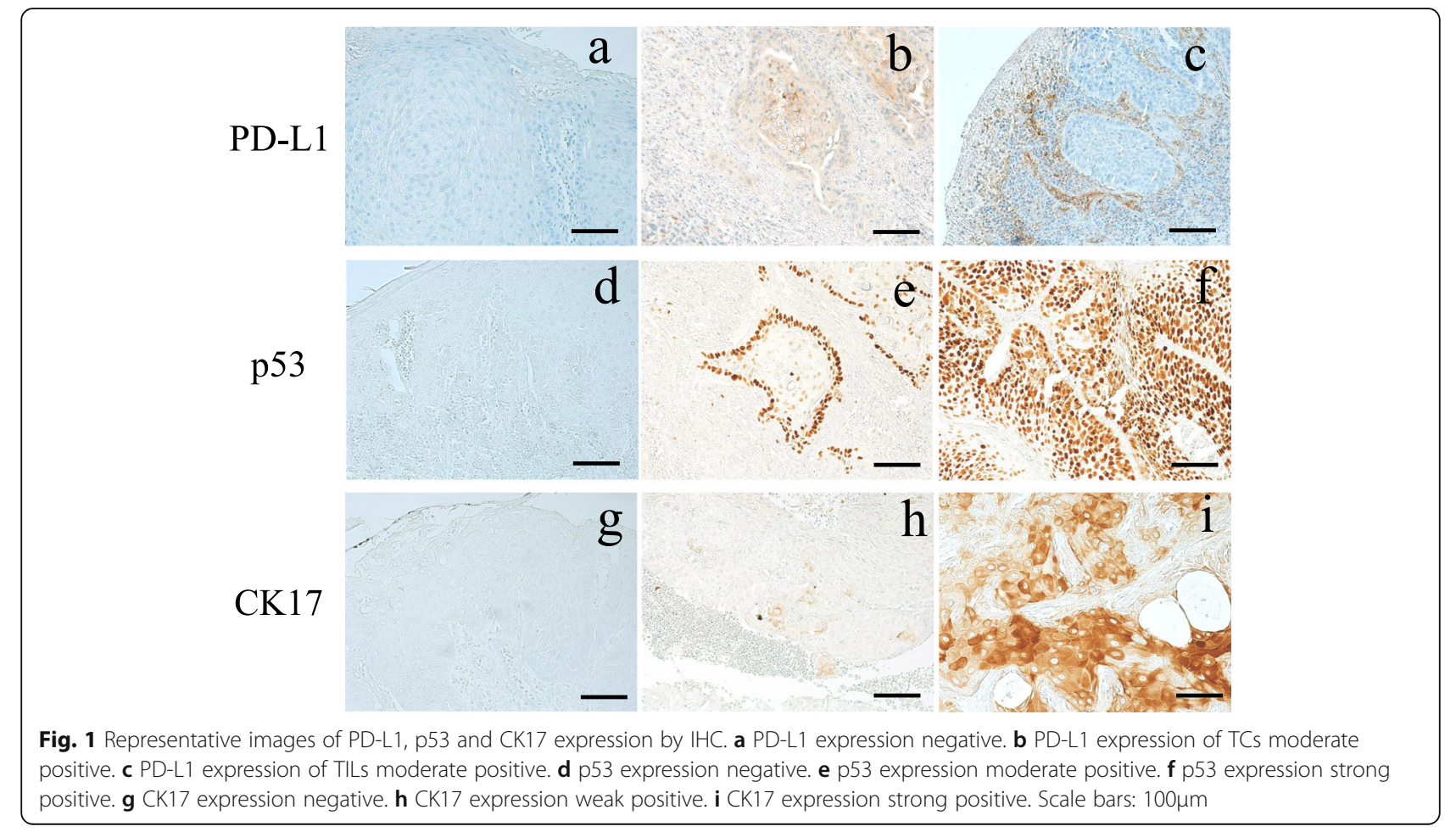


(TCs) based on previous larger studies (Fig.1a, b). Tumor-infiltrating lymphocytes (TILs) were considered to have positive PD-L1 expression if $\geq 1 \%$ of TILs exhibited moderate-to-strong membrane staining, as previously described (Fig. 1a, c) [7].

p53 expression was considered positive when $\geq 10 \%$ of the TC nuclei (Fig. 1d, e, f) [7].

The CK17-stained sections with $<5 \%$ reactive cells were considered to be negative, and those with more than $5 \%$ reactive cells were defined as positive (Fig. 1g, h, i) The sections were divided into two groups as follows: over 60 $\%$ positive cells were defined as "strong" cases; less than $60 \%$ positive cells were defined as "weak" cases [8].

The Chi-square $(x 2)$ test and Fisher's exact test were used to analyze differences in categorical variables (including gender, age, TNM stage, differentiation, mode of invasion) between positive PD-L1/P53/CK17 expression groups and negative PD-L1/P53/CK17 expression groups. In addition, univariate survival analysis and survival curves were conducted by Kaplan-Meier method

Table 1 Characteristics of PD-L1/p53/CK17 expression in patients with oral squamous cell carcinoma

\begin{tabular}{|c|c|c|c|c|c|c|c|c|c|c|c|}
\hline \multirow[t]{2}{*}{ Characteristics } & & \multirow[b]{2}{*}{ Cases } & \multicolumn{3}{|c|}{ PD-L1 expression in TCs } & \multicolumn{3}{|c|}{ p53 expression } & \multicolumn{3}{|c|}{ CK17 expression } \\
\hline & & & $\begin{array}{l}\text { Positive } \\
(\geq 5 \%)\end{array}$ & $\begin{array}{l}\text { Negative } \\
(<5 \%)\end{array}$ & $P$ value & $\begin{array}{l}\text { Positive } \\
(\geq 10 \%)\end{array}$ & $\begin{array}{l}\text { Negative } \\
(<10 \%)\end{array}$ & $P$ value & $\begin{array}{l}\text { Strong } \\
(\geq 60 \%)\end{array}$ & $\begin{array}{l}\text { Weak } \\
(<60 \%)\end{array}$ & $P$ value \\
\hline \multirow[t]{2}{*}{ Gender } & Male & 29 & 14 & 15 & 1.00 & 20 & 9 & 0.37 & 4 & 25 & 0.27 \\
\hline & Female & 20 & 10 & 10 & & 11 & 9 & & 6 & 14 & \\
\hline \multirow[t]{2}{*}{ Age } & $<65$ years & 22 & 12 & 13 & 1.00 & 15 & 10 & 0.76 & 5 & 20 & 1.00 \\
\hline & $\geq 65$ years & 27 & 12 & 12 & & 16 & 8 & & 5 & 19 & \\
\hline \multirow[t]{3}{*}{ T stage } & T1-T3 & 34 & 15 & 19 & & 18 & 16 & & 5 & 29 & 0.12 \\
\hline & $\mathrm{T} 4$ & 14 & 8 & 6 & 0.52 & 12 & 2 & $0.049^{*}$ & 5 & 9 & \\
\hline & Unknown & 1 & 1 & 0 & & 1 & 0 & & 0 & 1 & \\
\hline \multirow[t]{3}{*}{ N stage } & $N(+)$ & 20 & 10 & 10 & & 13 & 7 & & 4 & 16 & \\
\hline & $N(-)$ & 28 & 13 & 15 & 1.00 & 17 & 11 & 1.00 & 6 & 22 & 1.00 \\
\hline & Unknown & 1 & 1 & & & 1 & & & & 1 & \\
\hline \multirow[t]{3}{*}{ M stage } & MO & 48 & 22 & 25 & & 29 & 18 & & 0 & 1 & \\
\hline & M1 & 0 & 1 & 0 & 0.47 & 1 & 0 & 1.00 & 10 & 37 & 1.00 \\
\hline & Unknown & 1 & 1 & 0 & & 1 & 0 & & 0 & 1 & \\
\hline \multirow[t]{3}{*}{ TNM stage } & $|-|||$ & 30 & 13 & 17 & & 15 & 15 & & 4 & 26 & \\
\hline & IV & 18 & 10 & 8 & 0.55 & 15 & 3 & $0.03^{*}$ & 6 & 12 & 0.14 \\
\hline & Unknown & 1 & 1 & 0 & & 1 & 0 & & 0 & 1 & \\
\hline \multirow[t]{3}{*}{ Differentiation } & Well & 35 & 19 & 16 & & 20 & 15 & & 8 & 27 & \\
\hline & Moderate & 11 & 4 & 7 & 0.54 & 8 & 3 & 0.31 & 1 & 10 & 0.47 \\
\hline & Poor & 3 & 1 & 2 & & 3 & 0 & & 1 & 2 & \\
\hline \multirow[t]{5}{*}{ Mode of invasion } & Grade 1 & 3 & 2 & 1 & & 2 & 1 & & 2 & 1 & \\
\hline & Grade 2 & 9 & 4 & 5 & & 3 & 6 & & 1 & 8 & \\
\hline & Grade 3 & 17 & 9 & 8 & 0.96 & 11 & 6 & 0.21 & 3 & 14 & 0.37 \\
\hline & Grade 4C & 16 & 7 & 9 & & 11 & 5 & & 3 & 13 & \\
\hline & Grade 4D & 4 & 2 & 2 & & 4 & 0 & & 1 & 3 & \\
\hline \multirow[t]{2}{*}{ PD-L1 expression in TCs } & Positive & 24 & & & & 21 & 10 & $0.0009^{*}$ & 17 & 22 & 0.17 \\
\hline & Negative & 25 & & & & 3 & 15 & & 7 & 3 & \\
\hline \multirow[t]{2}{*}{ PD-L1 expression in TILs } & Positive & 28 & 21 & 7 & $<.0001^{*}$ & 21 & 7 & 0.07 & 20 & 19 & 0.15 \\
\hline & Negative & 21 & 3 & 18 & & 11 & 10 & & 8 & 2 & \\
\hline \multirow[t]{2}{*}{ p53 expression } & Positive & 31 & 21 & 10 & $0.0009^{*}$ & & & & 22 & 17 & 0.06 \\
\hline & Negative & 18 & 3 & 15 & & & & & 9 & 1 & \\
\hline \multirow[t]{2}{*}{ CK17 expression } & Weak & 39 & 17 & 22 & 0.17 & 22 & 17 & 0.06 & & & \\
\hline & Strong & 10 & 7 & 3 & & 9 & 1 & & & & \\
\hline
\end{tabular}


and the log-rank test was routinely used to test for significant differences.

\section{Results}

The differentiation degree was well differentiated in 35 cases, moderately differentiated in 11 and poorly differentiated in three cases. The mode of invasion was grade 1 in 3 cases, grade 2 in 9 , grade 3 in 17, grade $4 \mathrm{C}$ in 16 and grade $4 \mathrm{D}$ in 4 cases. Positive CK17, p53, PD-L1 (TCs) and PD-L1 (TILs) staining was present in $91.7 \%, 63.2 \%, 48.9 \%$ and $57.1 \%$ of all cases, respectively.

Table 1 shows the clinical and pathologic characteristics associated with PD-L1, p53 and CK17 expression. With respect to tumor stage, a statistically significant correlation between $\mathrm{p} 53$ expression and $\mathrm{T}$ stage and TNM stage ( $p=0.049, p=0.03$, respectively) was observed. Also, a statistically significant correlation between p53 and PD-L1 (TCs) expression $(p=0.0009)$ was observed. No other significant correlation between PDL1 staining or CK17 and clinical or pathologic characteristics was identified (Table 1).

However, the 5-year disease-specific survival rate by Kaplan-Meier method of the cases with PD-L1 (no expression) or CK17 (strong expression) tended to be slightly low, but not significant (Fig. 2a, b, d). Five-year disease-specific survival rate was not significantly correlated with p53 expression (Fig. 2c). The survival rate was not significantly correlated even with PD-L1 (+) and p53 (+).
Hazard ratio indicated that the 5-year disease-specific survival rate was not significantly correlated with gender, TNM stage, p53 expression, PD-L1 expression, and CK17 expression (Table 2).

\section{Discussion}

In this study, it is shown that the expression of PD-L1 is correlated with the expression of p53 in oral squamous cell carcinoma.

PD-L1 overexpression is recognized in many human cancers, promoting T-cell tolerance and escape host immunity. Early clinical trials using monoclonal antibodies that block the PD1/PDL1 interaction have shown promise in some patients with advanced cancer. OSCC patients with high PD-L1 expression had poor clinical outcome and might require PD-L1-targeted immunotherapy to improve their prognosis. Mutant p53 is present in almost all types of human tumor and is closely correlated with the development of OSCC. Mutated p53 loses its ability to suppress the function of oncogenes. Furthermore, mutant p53 may function as an oncogene to stimulate cell division and promote the growth of tumor cells [6].. Although whether p53 is involved in tumor immune evasion has been poorly understood, Cortez reported that PD-L1 is regulated by p53 via micro RNA (miR-34a) using a series of experiments involving lung cancer cell lines [15].

Regarding tumor cells, the expression of PD-L1 and p53 is positively correlated, because wild-type p53 is rapidly degraded $(\sim 0.5 \mathrm{~h})$; however, as the resolution time

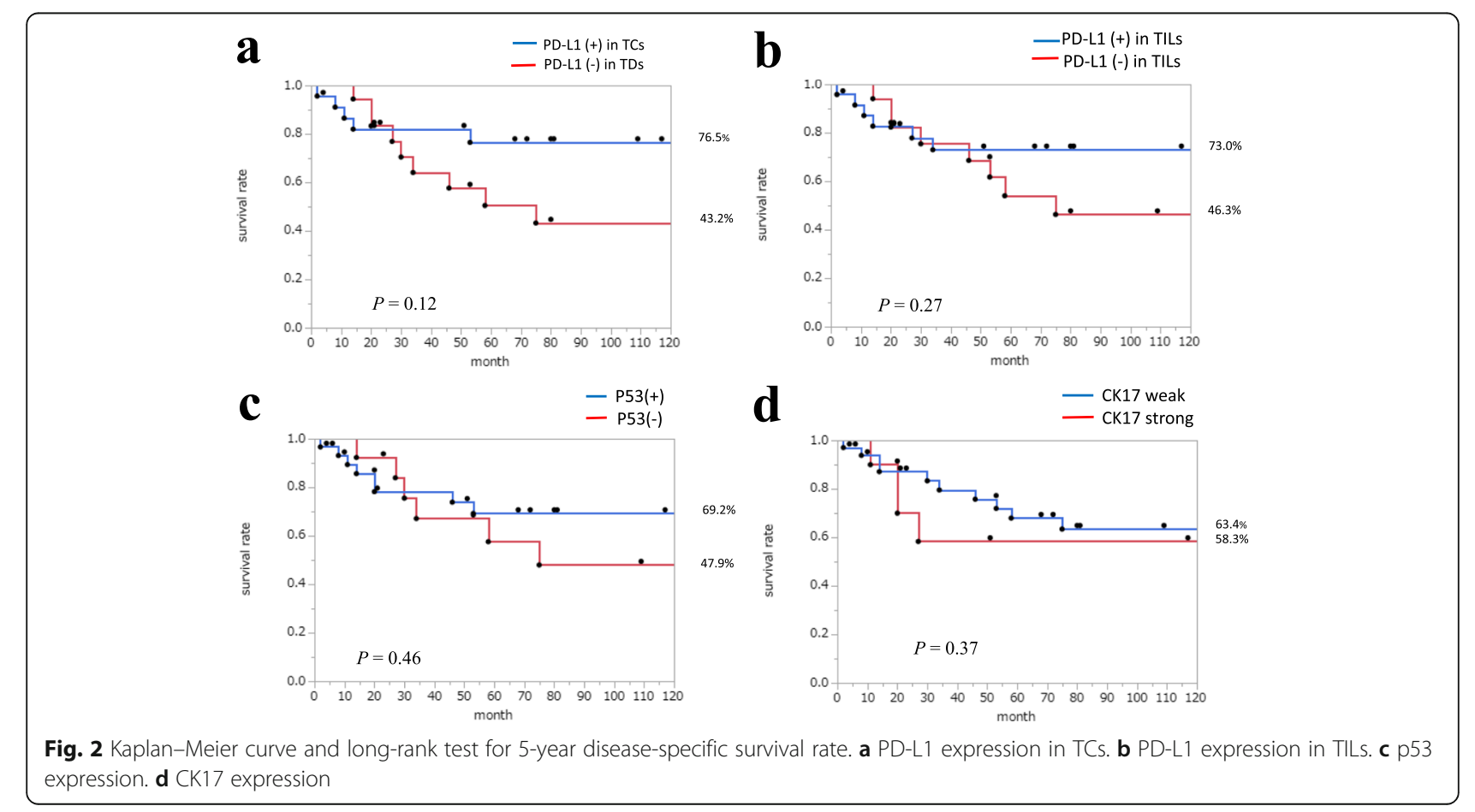


Table 2 Prognostic factors for disease-specific survival of the patients with oral squamous cell carcinoma according to multivariate analysis

\begin{tabular}{llll}
\hline Characteristics & Group & Hazard ratio $(95 \% \mathrm{Cl})$ & $P$ value \\
\hline Gender & Female/male & $0.389(0.094-1.610)$ & 0.193 \\
T stage & $\mathrm{T} 1-\mathrm{T} 3 / \mathrm{T} 4$ & $0.818(0.077-8.673)$ & 0.867 \\
$\mathrm{~N}$ stage & $\mathrm{N}(-\mathrm{-} / \mathrm{N}(+)$ & $0.860(0.262-2.829)$ & 0.805 \\
TNM stage & I-III/IV & $1.259(0.088-17.941)$ & 0.864 \\
PD-L1 expression in TCS & Positive/negative & $0.412(0.111-1.530)$ & 0.185 \\
P53 expression & Positive/negative & $0.655(0.176-2.440)$ & 0.528 \\
CK17 expression & Strong/weak & $3.418(0.806-14.49)$ & 0.095 \\
\hline
\end{tabular}

${ }^{*} P<0.05$ was defined as significant difference in statistical analysis

of variant p53 protein is delayed $(>2 \mathrm{~h})$ and the protein is accumulated in the nucleus, the variant p53 protein is identified as overexpression [16, 17]. Although wild-type p53 inhibits the expression of PD-L1 directly, when variant p53 which has lost a function is accumulated, PD-L1 is overexpressed. Thus, it is thought that the expressions of p53 and PD-L1 show positive correlation in oral squamous cell carcinoma in this study.

Furthermore, based on the results of Cancer Genome Atlas exome data analysis, there is a link between P53 status and mutation burden in tumors [18]. That is to say that the evaluation of P53 status could be used as a surrogate biomarker for mutation burden [19]. At the same time, although many different factors modulate the clinical response to an immune checkpoint inhibitor, the strong relationship between the tumor mutational burden and the activity of anti-PD-1 therapies across multiple cancers has been highlighted and the association of p53 and PD-L1 also suggested.

\section{Conclusion}

In this study, the expression of p53 and PD-L1 shows a positive correlation in oral squamous cell carcinoma in tumor cells for the first time. No other significant correlation between PD-L1 staining or CK17 and clinical or pathologic characteristics was identified.

\section{Abbreviations}

CK17: Cytokeratin 17; IHC: Immunohistochemistry; OSCC: Oral squamous cell carcinoma; p53: Protein 53; PD-L1: Programmed cell death ligand 1; TCs: Tumor cells; TILs: Tumor-infiltrating lymphocytes

\section{Acknowledgements}

This study was supported in part by a Grant-in-Aid for Scientific Research (16K11697) from the Japan Society for the Promotion of Science.

\section{Authors' contributions}

All authors read and approved the final manuscript. IT read and wrote the manuscript. IT, YS, TN, ME and FS performed most of the experiments. IT, KO and $\mathrm{YH}$ prepared retrospective data. YM revised and corrected the manuscript. IT and SF designed and wrote the entire article.

\section{Funding}

There is no funding related to this article.
Availability of data and materials

Please contact the author for data requests.

\section{Ethics approval and consent to participate}

This study followed the Declaration of Helsinki on medical protocol and ethics, approved by the regional ethical review board of Wakayama Medical University (Protocol Identification Number 2512). General consent was given by the patients.

\section{Consent for publication}

Not applicable.

\section{Competing interests}

The authors declare that they have no competing interests.

\section{Author details}

${ }^{1}$ Department of Oral and Maxillofacial Surgery, Wakayama Medical University, 811-1 Kimiidera, Wakayama, Wakayama 641-8509, Japan. ²Department of Dentistry and Oral Surgery, Japanese Red Cross Wakayama Medical Center, 4-20 Komatsubara-dori, Wakayama, Wakayama 640-8558, Japan. ${ }^{3}$ Department of Pathology, Wakayama Medical University, 811-1 Kimiidera, Wakayama, Wakayama 641-8509, Japan.

Received: 6 September 2019 Accepted: 6 November 2019

Published online: 05 December 2019

\section{References}

1. Sharmal P, Allison JP (2015) The future of immune checkpoint therapy. Science 348(6230):56-61

2. Maruse Y, Kawano S, Jinno T, Matsubara R, Goto Y, Kaneko N et al (2018) Significant association of increased PD-L1 and PD-1 expression with nodal metastasis and a poor prognosis in oral squamous cell carcinoma. Int. J. Oral Maxillofac. Surg 47:836-845

3. Lin YM, Sung WW, Hsieh MJ, Tsai SC, Lai HW, Yang SM et al (2015) High PDL1 Expression Correlates with Metastasis and Poor Prognosis in Oral Squamous Cell Carcinoma. PLoS ONE 10(11):e0142656. https://doi.org/10. 1371/journal.pone.0142656

4. Pfeifer GP, Holmquist GP (1997) Mutagenesis in the P53 gene. Biochim Biophys Acta 1333(1):M1-M8

5. Elias J, Dimitrio L, Clairambault J, Natalini R (2014) The p53 protein and its molecular network: modelling a missing link between DNA damage and cell fate. Biochim Biophys Acta 1844(1 Pt B):232-247

6. Li Y, Zhang J (2015) Expression of mutant p53 in oral squamous cell carcinoma is correlated with the effectiveness of intra-arterial chemotherapy. Oncol Lett 10:2883-2887

7. Yu X, Zhang X, Wang F, Lin Y, Wang W, Chen Y et al (2018) Correlation and prognostic significance of PD-L1 and P53 expression in resected primary pulmonary lymphoepithelioma-like carcinoma. J Thorac Dis 10(3):1891-1902

8. Kitamura R, Toyoshima T, Tanaka H, Kawano S, Kiyosue T, Matsubara R et al (2012) Association of cytokeratin 17 expression with differentiation in oral squamous cell carcinoma. J Cancer Res Clin Oncol 138:1299-1310

9. Xu XC, Lee JS, Lippman SM, Ro JY, Hong WK, Lotan R (1995) Increased expression of cytokeratins CK8 and CK19 is associated with head and neck carcinogenesis. Cancer Epidemiol Biomarkers Prev 4(8):871-876 
10. Toyoshima T, Vairaktaris E, Nkenke E, Schlegel KA, Neukam FW, Ries J (2008) Cytokeratin 17 mRNA expression has potential for diagnostic marker of oral squamous cell carcinoma. J Cancer Res Clin Oncol 134(4):515-521

11. Yamamoto E, Kohama G, Iwai M, Hiratsuka H (1983) Mode of invasion, Bleomycin sensitivity and clinical course in squamous cell carcinoma of the oral cavity. Cancer 51:2175-2180

12. Hiraishi Y, Wada T, Nakatani K, Negoro K, Fujita S (2006) Immunohistochemical Expression of EGFR and p-EGFR in Oral Squamous Cell Carcinomas. Pathol Oncol Res 12(2):87-91

13. Sato F, Bhawal U, Tojyo I, Fujita S, Murata S, Muragaki Y (2019) Differential expression of claudin-4, occluding, SOX2 and proliferating cell nuclear antigen between basaloid squamous cell carcinoma and squamous cell carcinoma. Mol Med Rep 20:1977-1985

14. Sato F, Kohsaka A, Takahashi K, Otao S, Kitada Y, Iwasaki Y et al (2017) Smad3 and Bmal1 regulate p21 and S100A4 expression in myocardial stromal fibroblasts via TNF-a. Histochem Cell Biol 148:617-624

15. Cortez MA, Ivan C, Valdecanas D, Wang X, Peltier HJ, Ye Y et al (2015) PDL1 Regulation by p53 via miR-34. J Natl Cancer Inst 108(1): djv303

16. Gronostajski RM, Goldberg AL, Pardee AB (1984) Energy requirement for degradation of tumor-associated protein p53. Mol Cell Biol 4:442-448

17. Finlay CA, Hinds PW, Tan TH, Eliyahu D, Oren M, Levine AJ (1988) Activating mutations for transformation by p53 produce a gene product that forms an hsc70-p53 complex with an altered half-life. Mol Cell Biol 8:531-539

18. Shim HS, Kenudson M, Zheng Z, Liebers M, Cha YJ, Ho QH et al (2015) Unique Genetic and Survival Characteristics of Invasive Mucinous Adenocarcinoma of the Lung. J Thorac Oncol 10:1156-1162

19. Cha YJ, Kim HR, Lee CY, Cho BC, Shim HS (2016) Clinicopathological and prognostic significance of programmed cell death ligand-1 expression in lung adenocarcinoma and its relationship with p53 status. Lung Cancer 97: 73-80

\section{Publisher's Note}

Springer Nature remains neutral with regard to jurisdictional claims in published maps and institutional affiliations.

\section{Submit your manuscript to a SpringerOpen ${ }^{\circ}$ journal and benefit from:}

- Convenient online submission

- Rigorous peer review

- Open access: articles freely available online

- High visibility within the field

- Retaining the copyright to your article

Submit your next manuscript at $\boldsymbol{\nabla}$ springeropen.com 